\title{
MICROCIRCULATION CHANGES IN THE AREA OF RESTORATION OF OSSEOUS DEFECTS OF JAWS USING POLYMERIC FIBROUS MATRIX
}

\author{
Andrii V. PANTUS ${ }^{1 凶}$, Nazar Ya. SLYUSARENKO ${ }^{1}$, Nataliia E. KOVALCHUK ${ }^{2}$, \\ Iryna R. YARMOSHUK ${ }^{3}$, Volodymyr L. KOGUT ${ }^{1}$ \\ ${ }^{1}$ Department of Surgical Dentistry of Ivano-Frankivsk National Medical University, Ivano-Frankivsk, \\ Ukraine \\ ${ }^{2}$ Department of Clinical Pharmacology and Pharmacotherapy of Ivano-Frankivsk National Medical \\ University, Ivano-Frankivsk, Ukraine \\ ${ }^{3}$ Department of Dentistry, Institute of Postgraduate Education of Ivano-Frankivsk National Medical \\ University, Ivano-Frankivsk, Ukraine
}

Received 7 Apr 2019, corrections received 21 June 2019, Accepted 15 July 2019

https://doi.org/10.31688/ABMU.2019.54.3.11

\begin{abstract}
Introduction. One of the most specific areas in practical dentistry is the use of various biological matrix structures that serve as a backbone for osteogenic cells and a framework for vascular components that provide the gradual formation of a new bone tissue in the area of defect formed by the resultant enucleation.

Objective. To establish the efficiency of using fibrous matrix and polymeric membrane in the process of restoration of defects of the bone structure after the procedure of the enucleation on the lower jaw and to analyze the results with those that were registered when performing bone defects with collagen sponge.

Materials and methods. The study was conducted in the Department of Surgical Dentistry of Ivano-Frankivsk National Medical University, Ukraine, during 6 months, between September 10, 2018-March 10, 2019. The selected sample of patients randomly were divided into two groups: $1^{\text {st }}$ group - the
\end{abstract}

\section{Résumé}

Changements de la microcirculation dans la zone de restauration des défauts osseux des mâchoires à l'aide d'une matrice fibreuse polymère

Introduction. L'un des domaines les plus spécifiques de la stomatologie pratique est l'utilisation de diverses structures de matrice biologique servant comme une épine dorsale aux cellules ostéogéniques et de cadre aux composants vasculaires assurant la formation progressive d'un nouveau tissu osseux dans la zone de défaut formée par l'énucléation résultante.

Objectif. Établir l'efficacité de l'utilisation de la matrice fibreuse et de la membrane polymère dans le processus de restauration des défauts de la structure osseuse après la procédure d'énucléation sur la mâchoire inférieure et analyser les résultats avec ceux enregistrés lors de la réalisation de défauts osseux avec une éponge de collagène. 
study group, which included 24 persons (filling the main bone defect in this group was carried out using the material developed by the authors, of fibrous matrix and polymer membranes); $2^{\text {nd }}$ group - the comparison group, in which 25 people were included (the completion of the main part of the bone defect in this group was carried out using CollaTape Collage Spot (Integra Life Sciences).

Results. The average index of reduction of the geometric radiological defect size in the research group was $89.4 \pm 2.5 \%$, while in the comparison group, this indicator was equal to $90.2 \pm 1.6 \%$. The largest reduction in both the research group and the comparison group was noted in the horizontal (87.8-93.6\%) and in the diagonal (88.4-91.5\%) components of the defect. Six months after the intervention, the index of reduction increased and reached 1.74 (72.50\%).

Conclusions. The absence of registered statistical differences between the above described criteria for assessing surgical treatment of patients in both groups suggests that the use of fibrous matrix and polymeric membranes does not provoke significant violations in the process of physiological bone regeneration after the removal of cyst.

Keywords: oral surgery, biopolymer, bioimplant, vascular tissue.

\section{List of abbreviations:}

$\mathrm{MeV}$ - mega electron volts

kGy - kilogray

RI - index of reduction

\section{INTRODUCTION}

The analysis of the peculiarities of etiology, clinical course and criteria for the diagnosis of odontogenic cysts, found that the prevalence of the latter according to previous research in the structure of inflammatory lesions of the maxillofacial area is 37, $2 \%$, with such formations occurring in almost every second patient who applied for surgical dental care. In the structure of the distribution of the prevalence of different types of nosological classification, the leading place is occupied precisely by radicular cysts, whose prevalence ranges from $85-90 \%$. Taking into account these data, development and improvement of effective surgical methods of treatment of odontogenic cysts remains an actual task of practical dentistry ${ }^{1-4}$.

However, the results of an examination indicate that only cystectomy procedures (exclusion of a defect with primary wound closure) are characterized by the lowest risk of associated complications. At the same
Matériaux et méthodes. L'étude a été réalisée sur une base de 6 mois, du 10 septembre 2018 au 10 mars 2019, au département de dentisterie chirurgicale de l'université nationale de médecine d'Ivano-Frankivsk. L'échantillon sélectionné de patients a été divisé au hasard en deux groupes: I groupe - la recherche, qui a porté sur 24 personnes (le comblement du principal défaut osseux de ce groupe a été réalisé à l'aide de l'article élaboré par les auteurs de la matrice fibreuse et des membranes polymères); II groupe - comparaison, comportant 25 personnes (l'achèvement de la partie principale des défauts osseux de ce groupe a été réalisé avec CollaTape Collage Spot (Integra Life Sciences).

Résultats. L'indice moyen de réduction de la taille du défaut radiologique géométrique dans le groupe de recherche était $89,4 \pm 2,5 \%$, tandis que dans le groupe de comparaison, cet indice était égal à 90,2 $\pm 1,6 \%$. La réduction la plus importante à la fois dans le groupe de recherche et dans le groupe de comparaison a été observée dans les composantes horizontale (87,8 à 93,6\%) et diagonale (88,4 à 91,5\%) du défaut. Six mois après l'intervention, l'indice de réduction (IR) augmentait et atteignait 1,74 , soit $72,50 \%$.

Conclusions. L'absence de différences statistiques enregistrées entre les critères décrits ci-dessus pour évaluer le traitement chirurgical des patients dans les deux groupes suggère que l'utilisation d'une matrice fibreuse et de membranes polymères ne provoque pas de violations significatives du processus de régénération osseuse physiologique après l'extirpation du kyste.

Mots-clés: chirurgie buccale, biopolymère, bio-implant, tissu vasculaire.

time, the authors point out only a small number of researches that were devoted to the direct comparison of the results of cystectomy without and with the subsequent fulfillment of the existing bone defect by bone substitutes of different origin ${ }^{5-7}$.

The use of collagen sponge, as a material for stabilizing the blood clot, practically does not affect the natural mechanism of filling formed in the results of bone defect enucleation, and can serve as a model for comparing the effectiveness of other approaches to optimizing surgical protocols for the treatment of patients with radicular cysts ${ }^{8-10}$. One of the specific directions in practical dentistry is the use of various biological matrix structures that lack the defects of bone substitutes and can act as a backbone for osteogenic cells and a framework for vascular components, which ensures the further gradual formation of a new bone tissue in the area of defect formed as a result of enucleation $^{11-13}$. 
THE OBJeCtIVE OF THE STUDY was to perform a microcirculation analysis using a fibrous matrix and a polymeric membrane in the process of restoring defects in the bone structure after the procedure for enucleation in the lower jaw and carry out an analysis of the results obtained with those that were registered in the application of bone defects with collagen sponges.

\section{Materials AND Methods}

The clinical stage of the research was conducted in the Ivano-Frankivsk National Medical University, Ukraine, with the formation of a sample of patients in accordance with the formulated inclusion criteria. The surgical operations and research were carried out at the Department of Surgical Dentistry of Ivano-Frankivsk National Medical University, Ukraine, during 6 months, between September 10, 2018-March 10, 2019. The criteria for inclusion of patients in the studied sample were as follows: 1) the finding of the defect of the bone tissue of the mandible associated with the tooth, with a diameter of more than $2 \mathrm{~cm}$, but less than $3 \mathrm{~mm}$; according to X-ray examination (orthopantomography); 2) possibility of diagnosis of «radicular jaw cyst», based on the data of the clinical examination, analysis of the data of anamnesis and results of X-ray diagnoses; 3 ) the absence of local or general contraindications to the procedure of cystectomy with the subsequent fulfillment of the formed defect by collagen sponge or fibrous matrix; 4) the possibility of carrying out the procedure for the enucleation of the area of the cyst and filling the formed defect with the preservation of the continuity of the mandible without the need for the use of additional osteosynthesis; 5) written consent of the patient regarding the protocol of the proposed treatment and further use of data for analysis with the provision of the principle of anonymity in the representation of the results.

The research was conducted with the involvement of 49 patients with a confirmed presence of bone tissue defect in the area of the lower jaw of odontogenic nature, which, taking into account the related clinical features and anamnesis data, could be classified as „radicular cyst“. Additional researches to confirm the histopathological diagnosis of "radicular cyst" were not conducted.

The selected patient sample was randomly assigned to two groups: Ist group - the study group, which included 24 persons (the filling of the main part of the bone defect in this group was carried out using the article developed by the authors of the fiber matrix and polymeric membranes); IInd group - the comparison group, which included 25 people (filling the main bone defect in this group was carried out using collagen sponge Colla Tape (Integra Life Sciences)). The age range of patients who participated in the research was 27-49 years of age, there was no statistically significant difference between the mean age of patients in the research group and the comparison group ( $\mathrm{p}<0.05)$.

Manipulation of enucleation in both groups was performed by one and the same physician according to the following protocol: anesthesia, separation of full-tissue bunch with its sufficient mobility, curettage of bone defect area with complete removal of all available granulations and cleaning of the bone surface, filling the main volume of the formed bone defect by fibrous matrix or collagen sponge, depending on the patient's belonging to the research group or the comparison group, the overlapping surface of the defect that a small portion of bone augmentation (Cera Bone, Botiss) of the membrane (Mucoderm, Botiss) followed sewing wound tightly. Removal of stitches was done after 10 days after the initial iatrogenic intervention.

Repeated clinical review of patients in both groups and X-ray control of changes in bone tissue, taking into account the principles of expediency of $\mathrm{X}$-ray loading, was performed in 6 months after the surgical stage.

Taking into account the use, in the research developed by the authors of the fiber matrix and polymer membrane, below is an algorithm for their obtaining and a description of the specificity of the structure. Fibrous non-woven matrix was made from polymer foams of polylactic acid Resorb X (KLS Martin), by the method of phase separation of the polymer (Fig. 1-2). The thickness of the fibrous matrix was $30 \mathrm{~mm}$ on average. The diameter of the fibers was from 4 microns to 10 microns.

Matrix was subjected to gamma sterilization. Hermetically sealed in a dual package for sterilization, the matrixes were evenly embedded in an electron beam with an energy of particles of 4 mega electron volts $(\mathrm{MeV})$ and a pulse width of 4.5 microseconds ( $\mu$ s). Each Medicom package is standardized in EN 868-5, ISO 11140-1, ISO 11607-1, in which the polymer was packed in a thickness of $0.6 \mathrm{~mm}$. At irradiation, the number of impulses varied from 4-70. The sterilization was based on the following parameters: the frequency of the accelerator was $250 \mathrm{~Hz}$, the maximum electron energy was $5 \mathrm{MeV}$, the maximum beam power was $5 \mathrm{~kW}$, pulse duration $4.5 \mu$ s, pulse current up to $1.5 \mathrm{~A}$, the power of braking radiation at a distance of $1 \mathrm{~m}$ from the target amounted to 104 $\mathrm{R} / \mathrm{sec}$. The radiation dose of the object was up to 50 $\mathrm{kGy}$ to calculate the volume and density of the material. According to the norm, the maximum allowable dose of $50 \mathrm{kGy}$, with a maximum electron energy of 


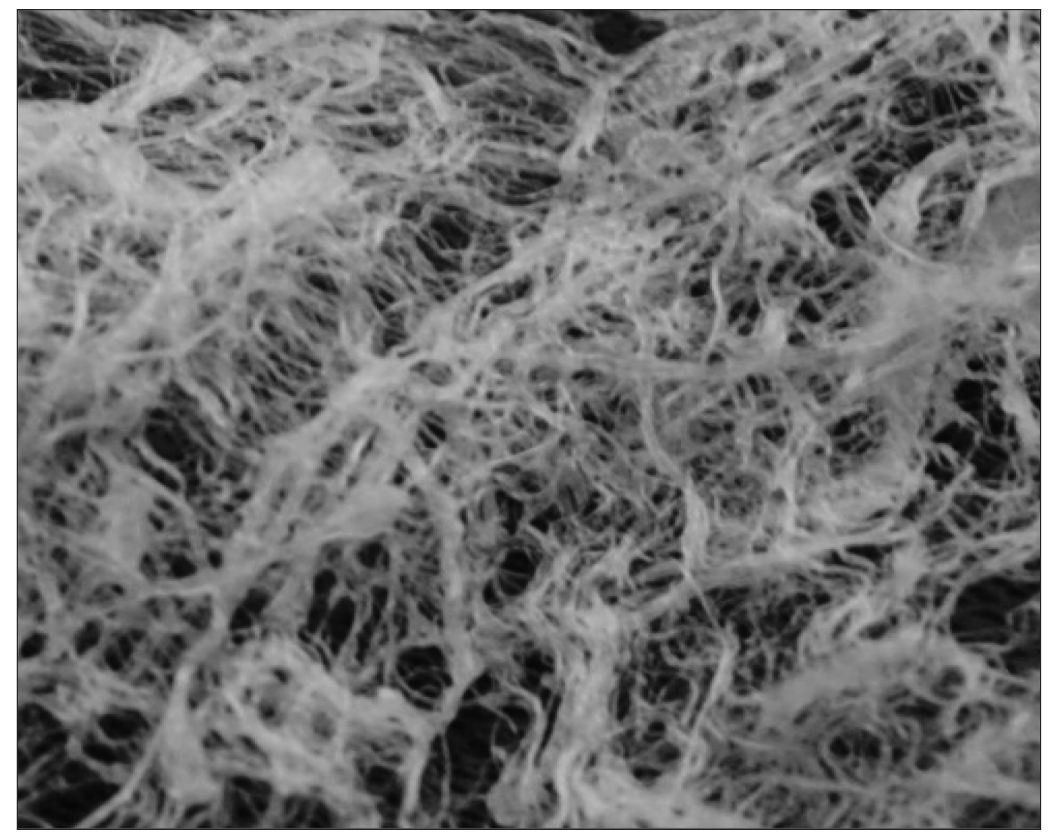

Fig.1. Fiber biopolymer matrix. Ob. 10, approx. 10

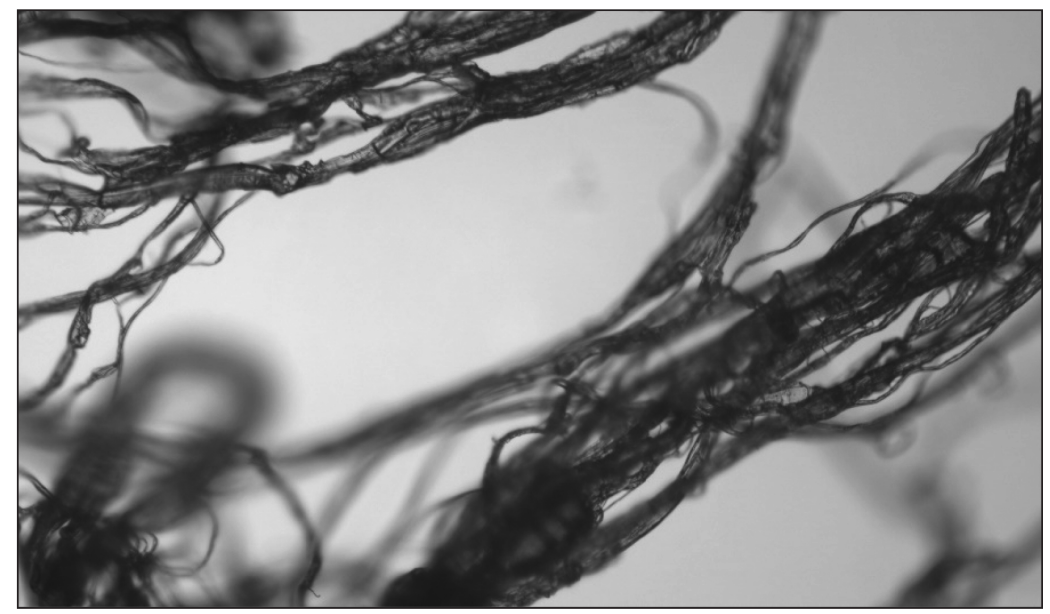

Fig. 2. Fiber biopolymer matrix. Ob. 10, approx. 10

$5 \mathrm{MeV}$. Processing by electrons with an energy of less than $10 \mathrm{MeV}$ did not cause nuclear transmutations, that is, did not lead to the formation of radioactive isotopes and did not create the residual radiation background radiation facility.

The polymeric membranes of the KLS Martin company were formed individually for the configuration of the bone surface by the method of thermo-vacuum pressing.

Measurement of bone defect size was performed by analyzing the results of X-ray researches using the algorithm described by Rubio E. D. and colleagues (2015) in the GIMP 2.10.8 (GNOME Foundation) software $^{14}$. In accordance with the method, the cysts were isolated by means of the Isolation tool, followed by the fragmentation of the resulting area from the general area of the image and the determination of the absolute planimetric dimensions of the defect (vertical, horizontal and two diagonal).

Analysis of the parameters of bone tissue in the area of the defect and surrounding bone areas was performed on the basis of the results of X-ray examination in Image J software (Wayne Rasband $(\mathrm{NIH})$ ) using the specialized plugin Bone $\mathrm{J}^{15}$. Using this plugin, the anisotropy parameters of bone tissue and the difference in the relative density of the filled area and the surrounding bone tissue were studied. The statistical processing of the results was carried out in the software Microsoft Excel 2016, which is part of the Microsoft Office 2016 software package. 


\section{Results}

As a result of a repeated clinical examination of patients in the research group and the comparison group, 6 months after the enucleation procedure, no complications associated with the infection site and associated inflammatory changes were detected. In addition, according to the criteria for inclusion of patients in the research, the size of the bone defect should be no more than $3 \mathrm{~cm}$ while maintaining the continuity of the structure of the mandible, which in turn also minimizes the risks associated with large cysts.

The average index of reduction (RI) of the geometric radiological defect size in the research group, in which the filling of the main part of the bone defect was carried out using the article of the fibrous matrix developed by the authors, was $89.4 \pm 2.5 \%$, while in the comparison group, this indicator was $90.2 \pm 1.6 \%$. At the same time, statistically, the difference between the average indices of reduction of the geometric radiographic size of the defect was not detected $(\mathrm{p}<0.05)$. The largest reduction in both the research group and the comparison group was noted in the horizontal $(87.8-93.6 \%)$ and in the diagonal (88.4-91.5\%) components of the defect.

Analysis of the parameters of bone tissue in the area of the defect and surrounding bone areas, which was carried out during the control examination based on the results of X-ray examination in the software Image J (Wayne Rasband (NIH)) using a specialized plug Bone J allowed to reveal the following indicators: the level of anisotropy of the completed area of the defect in the research group and the comparison group was 0.246-0.354 and 0.312-0.395 respectively (the statistical difference between the two groups was not detected $-p<0.05$ ); the difference in the relative density of the filled area and the surrounding bone tissue was $18.9-26.4 \%$ and $15.6-27.3 \%$ in the research group and the comparison group respectively (the statistical difference between the two groups was not found to be significant, $p<0.05$ ).

The correlation level between the parameters of changes in anisotropy parameters and the difference in relative density in the comparison group was 0.64 , and in the research group 0.67. It should be noted that the decrease of the anisotropy of the defect site in comparison with the data were registered at the moment of diagnosis in the research group was 0.523-0.634, and in the comparison group $0.495-0.655$; the primary density difference decreased in the research group by $59.3-68.4 \%$, and in the comparison group by $60.7-65.2 \%$.

Postoperative dynamics of rheographic indexes showed that within 1 month after the intervention of
$\mathrm{RI}$ in patients of group 1 did not differ from the same indicator in patients in group $2(\mathrm{p}>0.05)$. The time of rapid filling $\alpha / 1$ (blood flow index in large caliber vessels) in patients of 1 group has undergone large changes in the direction of generally accepted norms in comparison with a similar indicator in patients of 2 group, after a 6 -months period. The difference was $20.0 \%(p>0.05)$.

The temporal rate of vascular uptake of the medium and small caliber $\alpha / 2$ in patients in 1group experienced slight positive changes - it increased and remained unchanged throughout the research period. After surgical intervention, the volumetric blood flow rates of RI decreased to $42.08 \%$. The latter may be due to a decrease in the tone of arterioles and veins, which led to venous stasis. The only significant improvement of rheograms in 16 days after surgery is an increase in the geographic index to $53.75 \%$, indicating an increase in blood volume in tissues. A month after the surgery, the RI was $63.79 \%$ and time characteristics improved. Six months after the intervention, RI increased and reached 1.74 , which was $72.50 \%$. Significantly improved time periods of the functioning of vessels of large and medium caliber. There was still a fairly large value of $\alpha / 1$. The ratio of $\alpha / \mathrm{T}$ still showed venous stasis.

In one month after surgery, in all patients in 2 groups, the main indicator of blood supply to RI was reduced by $49.2 \%(\mathrm{p}<0.05)$. This is accompanied by a significant increase in the tone of the vessels of the large caliber and reduction of the tone of the arterioles and veins: $\alpha / 1$ exceeded 4.8-8.4 times ( $p$ $<0.05), \alpha / \mathrm{T}$ increased 3 times $(\mathrm{p}<0.05)$. This is due to insufficiency of perfusion of tissues. Only time of slow filling statistically significantly decreased by $13.7 \%$ ( $\mathrm{p}<0.05$ ). Most likely, this is due to the growth of a certain number of blood vessels, mostly larger caliber. The tendency towards the growth of RI (accordingly, for the improvement of postoperative periodontal blood flow) appeared at 6 months after surgery: RI was statistically significantly lower than the standard norm by $39.1 \%(\mathrm{p}<0.05)$. The rate of filling of $\alpha / 2$ vessels of medium to small caliber, unfortunately, did not undergo significant progress in the postoperative period. Sensitivity to hemodynamic changes after surgery was the ratio of $\alpha / T$. The fall of this indicator occurred gradually, and at the end of treatment decreased by 1.4 times ( $\mathrm{p}<0.05)$. The elasticity of the vessels of the large caliber is significantly reduced, blood supply (RI) was $57 \%$ of the lower limit of the standard norm. The tone of arterioles and veins is significantly reduced. The tone of large caliber vessels and peripheral resistance greatly increased against the backdrop of reducing the elasticity of large caliber vessels. Blood supply (RI) was $45.83 \%$ 
of the lower limit of norm. The tone of arterioles and veins has decreased, which is a sign of deterioration of venous outflow. Significant growth was observed ( $\mathrm{RI}$ is $54.58 \%$ of the norm), indicating an increase in the amount of blood in the bloodstream. In the postoperative period, there was a marked increase in the quantitative RI blood flow $(69.17 \%$ of the conditional norm), but the tone of large caliber vessels and peripheral resistance were still high against the backdrop of a reduced tone of arterioles and veins. Venous outflow is difficult. RI rose to $71.25 \%$ of the norm. At the same time, the tone of large caliber vessels and peripheral resistance remained elevated, and the arteriole and vein tone was reduced.

\section{Discussion}

The choice of material to replace the defect formed as a result of enucleation is based on a number of clinically meaningful and patient-associated factors, but in some cases, spontaneous regeneration of bone defect may be possible without the use of any auxiliary agents ${ }^{16-18}$. Data from preliminary clinical studies indicate the possibility of spontaneous and independent filling of defects in the bone structure of the jaws after the elimination of the main active pathological factor. In this case, the possibility of regeneration is largely determined by the ability of the formation of a new vascular network in the area of defect, the density of which in surrounding areas depends on the density of the bone tissue itself. On the other hand, the presence of well-formed walls of the bone defect in the lower jaw contributes to better stabilization of the blood clot, which is then subject to biological conversion ${ }^{19-21}$. Classically, during the first four weeks, osteogenic and angiogenic cells are migrating to the defect region from surrounding bone walls, together with the active period, contribute to the conversion of the formed blood clot into the granulation tissue, and subsequently into the immature rough-bone bone tissue ${ }^{3}$. The specific "hurray“ structure formed in the bone defect area begins to be determined approximately four months after the initial intervention, aimed at eliminating the pathological factor, which contributed to the formation and development of the defect ${ }^{10,12,22}$.

A retrospective multicentric research conducted by Lim (2017) made it possible to group the factors that, according to the analysis of authors, to the greatest extent lead to the loss of bone augmentation after the procedure for the exclusion of cysts in the maxillofacial area ${ }^{25}$. The use of the method of multivariant regression analysis contributed to the possibility of numerical representation of the increase in the relative risk of augmentation-associated complications after filling the defect site with a bone substitute, in the following cases: at a young age of the patient (relative risk - 1.033), in smoking (relative risk - 2.698), under post-operative infections (relative risk - 4.660), at large cysts (relative risk - 1.052), in case of sclerosis of the surrounding walls of the defect (relative risk 4.973), when using mixtures with autologous bone tissue or autologous augmentation in general (relative risk - 3.891). The latter risk factor is substantiated by the possibility of preliminary infection of the autologous material at the stage of its collection, which, if it is further blended with augmentation of another origin or isolated use, can automatically lead to the subsequent infection of the entire site of intervention ${ }^{23-25}$. From this point of view, the use of non-autological materials (collagen sponge or fibrous matrix) in order to fill bone defects formed as a result of enucleation is more appropriate.

\section{Conclusions}

As a result of the conducted research, it was found that the use of polymeric fibrous matrices and polymeric membranes for the purpose of filling defects of bone tissue after the exclusion of radicular-associated pathologies is characterized by a high level of success, which, according to the criteria used in the analysis, does not statistically differ from the results obtained in the accomplishment of similar defects with collagen sponge. Changes in the ratio of $\alpha /$ $\mathrm{T}$ may indicate metabolic changes in the tissues that are characteristics of the process of hydrolysis of the polymer.

\section{Compliance with Ethics Requirements:}

„The authors declare no conflict of interest regarding this article"

"The authors declare that all the procedures and experiments of this study respect the ethical standards in the Helsinki Declaration of 1975, as revised in 2008(5), as well as the national law. Informed consent was obtained from all the patients included in the study"

"No funding for this study"

\section{References}

1. Litvinets-Holutyak UYe, Rozhko MM. Modern peculiarities of etiological structure, clinical course and diagnostic criteria of odontogenic cysts. Galician Medical Journal. 2012; 19(4):153-157. [in Ukrainian].

2. Pradel W, Eckelt U, Lauer G. Bone regeneration after enucleation of mandibular cysts: comparing autogenous grafts from tissue-engineered bone and iliac bone. Oral Surg Oral Med Oral Pathol Oral Radiol Endod. 2006;101(3):285-290. 
3. Momeni Roochi M, Tavakoli I, Ghazi FM, Tavakoli A. Case series and review of glandular odontogenic cyst with emphasis on treatment modalities. J Cranio-Maxillofac Surg. 2015;43(6):746-50.

4. Etti T, Gosau M, Sader R, Reichert TE. Jaw cysts - filling or no filling after enucleation? A review. Journal of Cranio-Maxillofacial Surgery. 2012;40(6):485-493.

5. Zhao Y, Liu B, Wang SP, Wang YN. Computed densitometry of panoramic radiographs in evaluation of bone healing after enucleation of mandibular odontogenic keratocysts. Chin J Dent Res. 2010;13(2):123-6.

6. Araújo de Morais HH, José de Holanda Vasconcellos R, de Santana Santos T, Guedes Queiroz LM, Dantas da Silveira ÉJ. Glandular odontogenic cyst: case report and review of diagnostic criteria. J Craniomaxillofac Surg. 2012;40(2):e46-50.

7. Motooka N, Ohba S, Uehara M, Fujita S, Asahina I. A case of glandular odontogenic cyst in the mandible treated with the dredging method. Odontology. 2015;103(1):112-5.

8. Mitchell R. An evaluation of bone healing in cavities in the jaws implanted with a collagen matrix. British Journal of Oral and Maxillofacial Surgery. 1992;(30)3:180-182.

9. Brkovic BM, Prasad HS, Rohrer MD, et al. Beta-tricalcium phosphate/type I collagen cones with or without a barrier membrane in human extraction socket healing: clinical, histologic, histomorphometric, and immunohistochemical evaluation. Clinical Oral Investigations. 2012; 16(2):581-590.

10. Hayashi CN, Gudino CV, Gibson FC, Genco CA. Review: pathogen-induced inflammation at sites distant from oral infection: bacterial persistence and induction of cells pecific innate immune inflammatory pathways. Mol Oral Microbiol. 2010;25(5):305-316

11. Meshram VS, Lambade PN, Meshram PV, Kadu A, Tiwari MS. The autologous platelet rich fibrin: A novel approach in osseous regeneration after cystic enucleation: A pilot study. Indian J Dent Res. 2015;26(6):560-564.

12. Dar M, Hakim T, Shah A, Najar L, Yaqoob G, Lanker F. Use of autologous platelet-rich fibrin in osseous regeneration after cystic enucleation: A clinical study. J Oral Biol Craniofac Res. 2016; 6(Suppl 1):S29-S32.

13. Buchbender M, Neukam FW, Lutz R, Schmitt CM. Treatment of enucleated odontogenic jaw cysts: a systematic review. Oral Surgery, Oral Medicine, Oral Pathology and Oral Radiology. 2017;125(5):399-406.

14. Rubio ED, Mombru CM. Spontaneous bone healing after cysts enucleation without bone grafting materials: a randomized clinical study. Cranio-maxillofacial Trauma $\mathbb{E}$ Reconstruction. 2015;8(01):14-22.

15. Doube M, Kłosowski MM, Arganda-Carreras I, et al. Bone $\mathrm{J}$ : free and extensible bone image analysis in ImageJ. Bone. 2010;47(6):1076-1079.

16. Chiapasco M, Rossi A, Motta JJ, Crescentini M. Spontaneous bone regeneration after enucleation of large mandibular cysts: a radiographic computed analysis of 27 consecutive cases. Journal of Oral and Maxillofacial Surgery. 2000; 58(9):942-948.

17. Chacko R, Kumar S, Paul A, Arvind. Spontaneous bone regeneration after enucleation of large jaw cysts: a digital radiographic analysis of 44 consecutive cases. J Clin Diagn Res. 2015;9(9):ZC84-ZC89.

18. Gerlach KL, Niehues D. Treatment of jaw cysts with a new kind of nanoparticular hydroxylapatite. Mund Kiefer Gesichtschir. 2007;11(3):131-7.

19. Levarek RE, Wiltz MJ, Kelsch RD, Kraut RA. Surgical management of the buccal bifurcation cyst: bone grafting as a treatment adjunct to enucleation and curettage. J Oral Maxillofac Surg. 2014;72(10):1966-73.

20. Korn P, Hauptstock M, Range U, et al. Application of tissue-engineered bone grafts for alveolar cleft osteoplasty in a rodent model. Clin Oral Investig. 2017;21(8):2521-2534.

21. Pradel W, Lauer G. Tissue-engineered bone grafts for osteoplasty in patients with cleft alveolus. Ann Anat. 2012; 194(6):545-8.

22. Korn P, Schulz MC, Range U, Lauer G, Pradel W. Efficacy of tissue engineered bone grafts containing mesenchymal stromal cells for cleft alveolar osteoplasty in a rat model. J Craniomaxillofac Surg. 2014:42(7):1277-85.

23. Perjuci F, Ademi-Abdyli R, Abdyli Y, et al. Evaluation of spontaneous bone healing after enucleation of large residual cyst in maxilla without graft material utilization: case report. Acta Stomatol Croat. 2018;52(1):53-60.

24. Wagdargi SS, Rai KK, Arunkumar KV, Katkol B, Arakeri G. Evaluation of spontaneous bone regeneration after enucleation of large cysts of the jaws using radiographic computed software. Journal of Contemporary Dental Practice. 2016;17(6):489-495.

25. Lim HK, Kim JW, Lee UL, Kim JW, Lee H. Risk factor analysis of graft failure with concomitant cyst enucleation of the jaw bone: A retrospective multicenter study. Journal of Oral and Maxillofacial Surgery. 2017;75(8):1668-1678. 